\title{
Development of an approach to the environmental and economic assessment of the effectiveness of changing the traffic management regime
}

\author{
Ivan Novikov ${ }^{1}$, Victoria Vasilyeva $^{2}$, Andrei Kravchenko ${ }^{3}$, and Anastasia Shevtsova ${ }^{1 *}$ \\ ${ }^{1}$ Belgorod State Technological University named after V.G. Shukhov, 308012 Belgorod, Russia \\ ${ }^{2}$ Orel State University, 302026 Orel, Russia \\ ${ }^{3}$ Management of the state inspection of safety of traffic of the Ministry of internal Affairs of Russia \\ across the Belgorod region, 308014 Belgorod, Russia
}

\begin{abstract}
The paper investigates the main approaches, applied in the process of assessment of efficiency of changing the traffic management regime. The main parameters, which make the evaluation of effectiveness possible, have been figured out and set, the research has been performed to identify and define these parameters within a framework of the specific object of study, i.e. a controlled intersection in the urban, regional centre. The particular approach, allowing to assess eco-economic efficiency of the alteration of the control and management mode in accordance with such parameters as the saturation level, delay of the vehicles (traffic delays), fuel consumption, amount of harmful toxic emissions, has been successfully developed, the natural and model experiments have been carried out, the prospects and recommendations for an application of this approach have been formulated.
\end{abstract}

\section{Introduction}

In the process of choosing an optimal regulatory regime, the question of evaluation of its effectiveness arises. Today, due to rapid motorization, our attention is focused on intelligent transport systems and use of telematics devices during their implementation [1-3]. The method of forced control and management of traffic flows, i.e. traffic-lights controlled junctions, is considered to be one of the main blocks of introduction and implementation of such systems and devices. A lot of studies are aimed at improving the methods and approaches of defining the optimum duration of the control cycle, which helps us to reduce waiting time of the crosswalk signal and, thus, offload traffic flow. It is particularly important at difficult intersections, where there is always the need to untie a traffic jam.

Studies, conducted earlier, showed, that an enormous amount of the factors, which should be taken into consideration, have an impact upon the control and regulation regime. So, one of the aspects of the research is to determine the heterogeneity of the rolling stock, which is

* Corresponding author: shevcova-anastasiya@mail.ru 
dynamic, and constantly changes its values over time [4-5]. The group of the authors has developed the method of accounting of this indicator and has tested this figure at international conferences. When using a new approach and performing the model experiment, reduce of delays and latency of the vehicles has been achieved, which proves the effectiveness of the approach.

The method of evaluation of traffic delays reduction is used for assessing the results of implementation of new regimes of the transport flows, but in order to achieve a high and positive effect there is a need for applying the method of eco-economic assessment, therefore, this approach has been thoroughly studied and developed in the framework of this research. The approach will definitely help us to define and indicate the ecological and economic aspects of the change of control and management regimes.

\section{Formation of eco-economic techniques of evaluation of the control and management mode change}

The quality of different traffic management schemes, as well as checking of various durations of regulatory regimes at intersections, are estimated by means of an average (approximate) delay of cars, this indicator depends proportionally on the degree of saturation of $x$ directions. This value is dimensionless and limitless, its physical meaning is in the ratio of the average number of the cars, arriving at the crossing (intersection) during the whole cycle, to the maximum of the cars, which have started driving during the crosswalk signal, it directly depends on the size of saturation flow, which will help to assess the impact of changes in the control and management regime. In accordance with the legal acts, degree of saturation is defined by the formula:

$$
x=N_{j} T_{c} /\left(M_{H j} t_{o j}\right),
$$

where $N_{j}$ and $M_{r j}$ denote traffic density and saturation flow, $\mathrm{u} / \mathrm{h} . ; T_{c}-$ denotes duration of the cycle, s.; $t_{o j}$ - denotes duration of the basic tact, s.; $j$ - denotes the destination (direction) number.

The definition of this magnitude (value) assists us with evaluation of the method of traffic flow control and management from the point of view of conjection of the vehicle lanes, if a value approaches (is close to) 1 , respectively, during the crosswalk signal (the signal which is being used), so, the maximum possible number of cars leaves the crossroads ( the intersection), if the value exceeds 1 , so, the selected regime of control is not fully effective, due to the fact that for a certain period of time (the duration of the crosswalk signal) some cars can't leave the crossroads, which will cause the delays.

The analysis of control and management efficiency in accordance with the parameter, which has been offered above, will help us indicate and define feasibility of the applied regime in accordance with the results of the calculation of the value under consideration and investigation beforehand (before the stage of implementation).

In software, for example in Transyt - 7FR, the value of the delay of control is calculated by the following formula [6]:

$$
d=d_{1} P F+d_{2}+d_{3},
$$

where: $d_{l}$ - is a homogeneous delay, s/auto; $P F$ - is the coefficient of adjustment and correction of the possibility of unimpeded (free), and smooth movement; $d_{2}$ - denotes the random (ad hoc) delay, s/auto; $d_{3}-$ is the residual delay, s/auto.

As $d_{l}$ is calculated by integrating the profile of the module of queue, so, we accept the $\mathrm{PF}$ value to be equal to 1 . Therefore, the delay in the programme is calculated as the sum of three components, similar to the classic calculation according to the F. Webster formula [7]: 


$$
t_{\Delta p}=\frac{T_{c}(1-\lambda)^{2}}{2(1-\lambda x)}+\frac{x^{2}}{2 N(1-x)}-0,65\left(\frac{T_{c}}{N^{2}}\right)^{1 / 3} x^{(2+5 \lambda)},
$$

where $t_{\Delta p}$ - is the average delay per cycle, $\mathrm{s} ; T_{c}$ - is the duration of the regulatory cycle, $\mathrm{s} ; x$ - denotes the level of saturation; $\lambda$ - denotes the ratio of duration of the crosswalk signal (enable signal) to the cycle; $N$ - denotes traffic intensity in the direction under analysis, $\mathrm{u} / \mathrm{s}$.

The ratio of duration of the crosswalk signal (enable signal) to the cycle will be denoted and calculated for each regulation phase according to the formula:

$$
\lambda=\frac{t_{o j}}{T_{c}}
$$

The first part of formula 3 helps us to define the delay of cars in the process of arriving at the crossroads. The second part takes into account the random nature of the arrival and allows determining the average latency in this direction of the intersection. The third helps to take into account the margin of error during calculation of the delay in accordance with the first two components.

In the simulation programme, entitled Transyt-7FR, fuel consumption is estimated on the basis of the linear combination of full mileage, delays and stoppages. The acquired value of fuel consumption comprises fuel, used while driving, moving at low idling speed, and during acceleration and braking (high accelerating and stopping capability). The mathematical model for calculation of fuel consumption according to the H. Loriksa and K. Vjelisa's research is represented in the following way [8]:

$$
F=K_{i 1} \cdot T T+K_{i 1} \cdot D+K_{i 3} \cdot S,
$$

where $F$ denotes fuel consumption, $1 / \mathrm{h}$; $T T$ denotes the total mileage in a car $-\mathrm{km} / \mathrm{h} ; D$ is the full, complete delay, auto/h; $S$ denotes a complete amount of stoppages per hour; $K_{i j}$ are the coefficients of the model, serving and operating as the functions of cruising speed $\left(V_{i}\right)$ on each $i-$ th segment.

Using simulation programme, we may obtain the values of fuel consumption for each direction under the current and proposed control and management mode, which helps us to compare the results and economic benefits at the expense of and by means of fuel economy on the object.

Fuel economy will be calculated according to the formula:

$$
E_{\text {fuel }}=C O N_{\text {current }}-C O N_{\text {complete }},
$$

where $C O N_{\text {current }}$ denotes average fuel consumption under the current regulatory regime, $\mathrm{l} / \mathrm{h}$; $C O N_{\text {complete }}$ denotes average fuel consumption under the acquired regulation regime, $1 / \mathrm{h}$.

Specific fuel consumption value allows us to estimate the reduction of losses, caused by air pollution.

Economic costs of air pollution, caused by harmful substances, coming from the toxic fumes and gases from cars during the year on a particular stretch of highway, according to V.A. Korchagin's research $[9,12]$, are calculated when we take into account the specific emission of harmful substances (HS), and are estimated to be $1000 \mathrm{t} / \mathrm{km}$ of mileage or $\mathrm{g} / 1$ $\mathrm{km}$ of mileage:

$$
C_{3}=\frac{0,365 L N_{r h}}{k_{u}} \sum D_{s p i} C_{s p i} b_{i},
$$

where $L-$ is the length of the highway, $\mathrm{km} ; N_{r h}$ is intensity of movement of a specific type of cars in rush hour, auto/h; $m$ - is the coefficient, which takes into account the increased fuel 
consumption when moving with frequent stoppages; $k_{u}$ is the coefficient of uneven motion $\left(k_{u}=0,1\right) ; D_{s p i}$ denotes specific emission of harmful substances; $C_{s p i}$ denotes specific damage, caused by emission of harmful substances, $\mathrm{p} / 1$ substances; $b_{i}$ is the coefficient, which takes into account the influence of the technical condition of the vehicle on the emission of harmful substances (if the data are absent, so, you can assume that $b_{i}=1$ ).

According to the instructions for the calculation of emissions [10] in the process of burning of $1 \mathrm{~kg}$ of petrol for cars of ecological class above Euro 1, the specific emission of major pollutants comprises:

- Carbon monoxide (CO) - 21,5 g. $/ \mathrm{kg}$.

- Hydrocarbons in terms of CH1.85 (including VOC, which fuel sprays contain) (VOC) $-2,4 \mathrm{~g} . / \mathrm{kg}$.

- Nitrogen oxides in terms of NO2 (NOx) - 5,8 g./kg.

- Sulphur dioxide (SO2) - 0,54 g./kg.

- Carbon dioxide (CO2) - $3120 \mathrm{~g} . / \mathrm{kg}$.

If we know the amount of fuel consumption at each of the intersections and the nominal value in the process of burning of $1 \mathrm{~kg}$ of fuel [11], we may figure out the values of harmful substances during the application of the existing and the proposed regulation modes.

Moreover, according to the analysis of the legal acts and fundamental approaches to the assessment of the effectiveness of control and management regime, we have formulated the techniques and methodology of estimation of the ecological and economic efficiency in the situation of introducing some changes into the plan of management and regulation of traffic lights (fig.1)

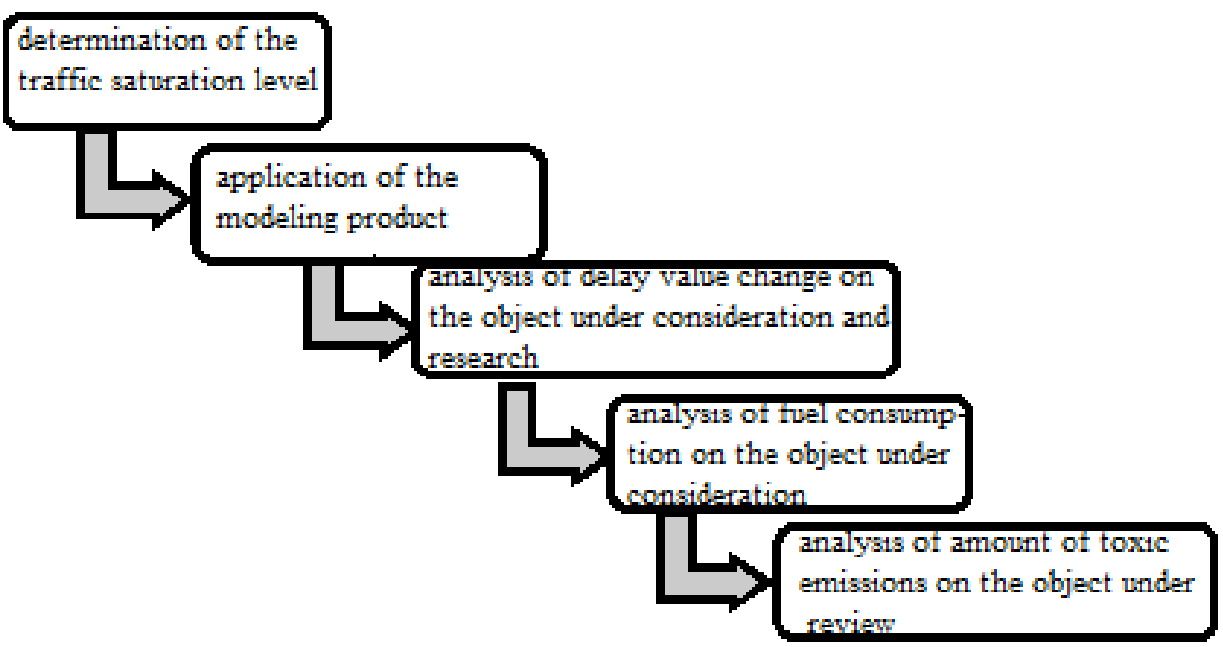

Fig. 1. Techniques (methodology) of eco-economic evaluation of traffic flow management and control mode changes in the process of using the traffic lights

In order to put the formulated method to test and practice the group of scientists (the authors of this paper) have conducted the model experiment at one of the busiest intersections in Belgorod.

\section{The experiment}

The intersection, connecting such streets as Gubkin Street-Sport Street-Arhijerejskaya Street (fig. 2), are considered to be the most difficult for movement 


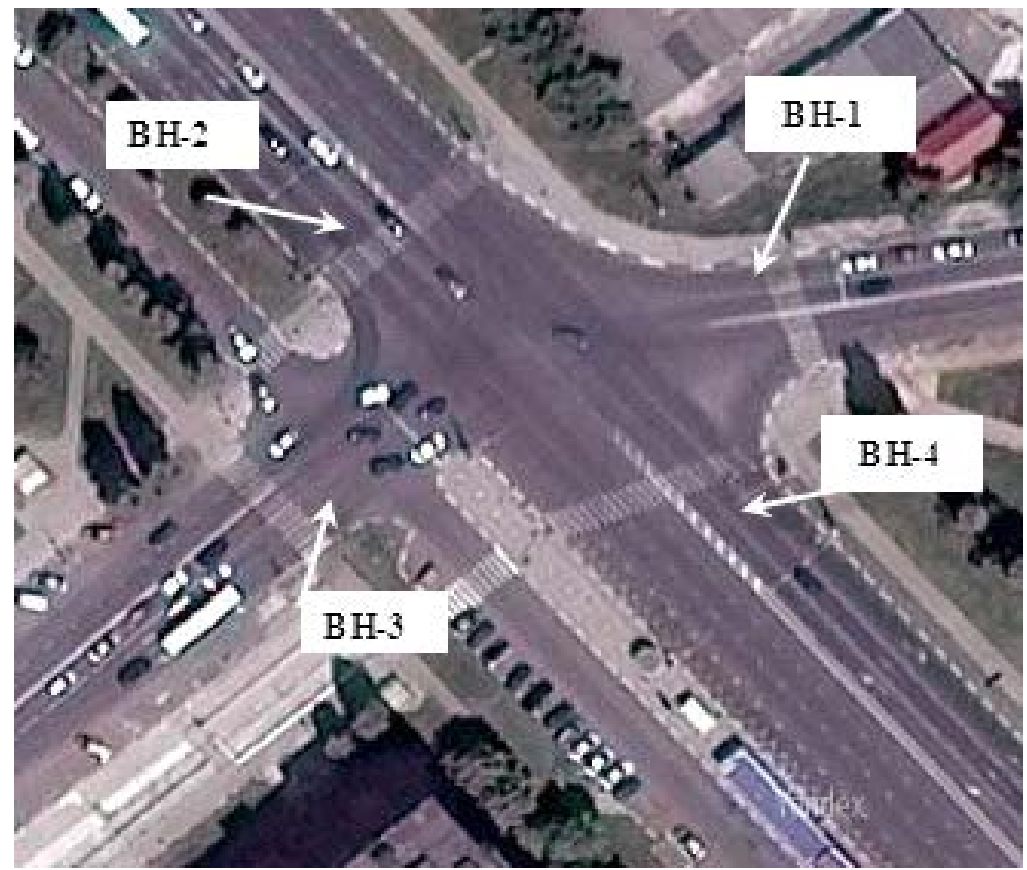

Fig. 2. Satellite image and photo of the junction (crossroads) of such streets as Gubkin Street-Sport Street-Arhijerejskaya Street(Belgorod) with the designation of entry directions

The method of defining of an effective control and management regime, which have been developed earlier, helps us to calculate the duration of the regulation cycle; the main parameters have been calculated in accordance with the developed approach to ecological and economic assessment. These calculations have shown the areas and directions with traffic jams (oversaturated directions), (such as $12 \mathrm{BH}, \mathrm{BH}, \mathrm{BH} 41$ 13), because saturation level is $>1$. Moreover, probability of traffic jams in the majority of directions is very high, because $x$ value is located in the limit (borders), in a range of $0,9 \ldots 1,0$. These directions are $11 \mathrm{BH}$, $32 \mathrm{BH}, 33 \mathrm{BH}, 22 \mathrm{BH}, 23 \mathrm{BH}, 42 \mathrm{BH}$. The acquired and obtained values of the degree of saturation in the framework of the existing regime have turned out to be unsatisfactory at the intersection under investigation (fig. 3).

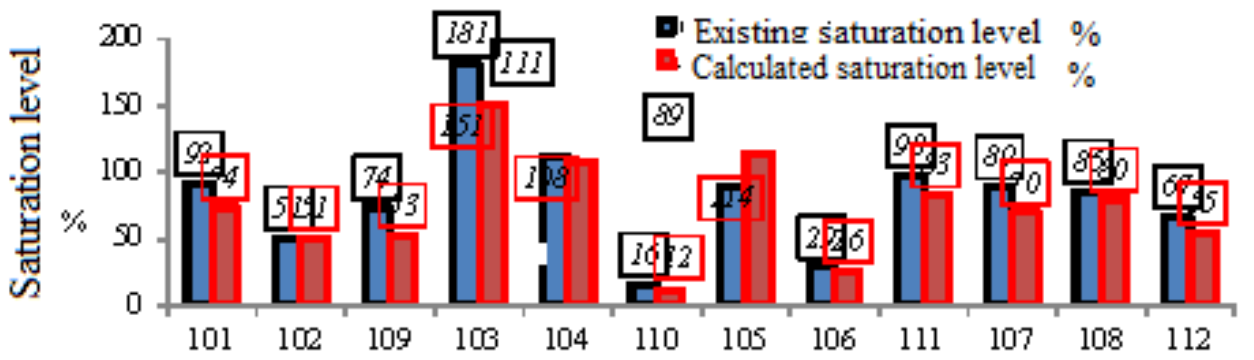

Fig. 3. A graph of changes of the degree of saturation in the directions of the regulated intersection

Considering the value of $x$ during the operation of the mode, described in this paper, it becomes clear that the situation is improving in almost all directions, despite the fact that some areas and directions remain in supersaturated state, i.e. city jams are huge there, an average value of deflection is equal to 0,18 , out of minimum and maximum value in a range of $0-0,34$ respectively. Deviation of acquired values reaches approximately $8,3 \%$. 
Considering all destinations at the crossroads, we can say that during the peak period in the process of operation of the existing mode the average latency value has reached $87,4 \mathrm{~s}$, this value has decreased and become equal to $79.1 \mathrm{~s}$. during the operation of the calculated regime, and the average value of deviation is about $8 \%$.

Decrease in average delay (latency) time per cycle amounted to $32 \%$ in all the directions in each phase of regulation, which signals and proves efficiency of the performed experiments and actions as well as effectiveness of the calculated regime.

Annual economic effect is calculated with a help of the formula:

$$
E=E_{f} \cdot C_{A I-92} \cdot K_{u} \cdot D
$$

where $E_{f}$ denotes economy of fuel, $1 . / \mathrm{h} ; C_{A I-92}$ is the cost of 11 of gasoline AI-92, rub.; $K_{u}$ is the coefficient of uneven motion of traffic flow within the range of $0,1 \ldots 0,36 ; D$ denotes the number of the days of the year.

$K_{u}=0,25$ is used for calculation of annual economic effect according to the natural researches and experiments [11]. Calculation of annual fuel savings was made using the average cost of gasoline AI-92 equal to 36.00 rubles.

Calculation of annual savings on the intersection reached the amount of 1.5 million rubles per year, assuming that the calculated regime will be operating during the peak period (rush hour), namely in the morning rush hour from 8.00 up to 10.00 , in the afternoon rush hour from 11.00 up till 13.30 and in the evening rush hour from 17.00 up till 20.00.

If we know the amount of fuel consumption and flow and the nominal value in the process of burning of $1 \mathrm{~kg}$. of fuel $[10,11]$, so, the value of the harmful substances during the operation of the present, existing and the calculated control and management modes has been defined.

According to the data, received in the framework of this research, emissions of toxic substances decrease if we take into consideration all the CP (calculated parameters), thus, if we used the modes, represented in the paper, during the year we would reduce and cut carbon monoxide emission by 0.837 t., hydrocarbon by 0.093 t., nitrogen oxides by 0.226 tons and sulphur dioxide by 0.021 tonnes.

\section{Conclusion}

The designed and developed ecological and economic approach of assessment of change of control and management regime at the regulated crossroads (intersection) helps us to define the main difficult directions in accordance with the analysis of the value, amount and the magnitude of flow and saturation and declare efficiency of the applied regime (mode). According to this approach, the main economic indicators can be figured out after evaluation of effectiveness, and in case the delays of cars are absent, namely fuel consumption during the application of simulation modeling programmes. When the economic efficiency indicator has been measured, it is possible to calculate environmental indicators with an assessment of their cost.

While performing analysis of ecological and economic parameters on the regulated crossroads in Belgorod we have come to the conclusion, that change of the control and management regime has an impact upon them. The application and implementation of the developed approach and the conducted analysis within the framework of the changes of the plans of control on the example of the urban agglomeration will assist us with an opportunity for evaluating the scale of the environmental and economic impact of road transport on the city ecosystem and develop recommendations for improving the core indicators of traffic.

The article has been prepared within the framework of the development of the core, basic university on the basis of BSTU named after V.G. Shuhov. 


\section{References}

1. A.N. Novikov, A.L. Sevost'yanov, A.A. Katunin, A.V. Kulev, Primeneni eintellektual'nykh transportnykh sistem (ITS) dlya povysheniya effektivnosti funktsionirovaniya gorodskogo obshchestvennogo transporta [Application of intellectual transport systems (ITS) for increase of operation and functioning of urban public transport] 6 Mir transporta i tekhnologicheskikh mashin [The world of transport and technological machines, no 1(40), pp. 85-90 (2013)

2. A.N. Novikov, A.A. Katunin, V.V. Vasil'eva, D.D. Matnazarov, Intellektualizatsiya dorozhnogo dvizheniya na ulitse Naugorskoe shosse gorodaOrla [Intellectualization of traffic on Naugorskoe Highway in Oryol]6 V sbornike: GLONASS - Regionam pod obshcheiredaktsiei A.N. Novikova [IntheEdition: GLONASS-Regions,ed.A. N. Novikov]. Oryol, pp. 48-54 (2014)

3. A.E. Borovskoi, I.A. Novikov, A.G. Shevtsova, Vnedrenie intellektual'nykh transportnykh sistem $v$ ramkakh natsional'nykh program povysheniya bezopasnosti dorozhnogo dvizheniya [Implementation of intelligent transport systems in the framework of national programmes, aimed at improving road safety]. Vestnik, no 6162, pp. 279-283 (2013)

4. A. Novikov, I. Novikov, A. Katunin, A. Shevtsova, Adaptation capacity of the traffic lights control system (TSCS) as to changing parameters of traffic flows within intellectual transport systems (ITS). Transportation Research Procedia, 20, pp.455 462 (2017)

5. A. Novikov, I. Novikov, A. Katunin, A. Shevtsova, Research of influence of dynamic characteristics for options controlled intersection. Procedia Engineering, 187, pp. 664 - 671 (2017)

6. D.I. Robertson, TRANSYT: Traffic Network Study Tool. Fourth International Symposium on the Theory of Traffic Flow, Karlsruhe, Germany (1968)

7. F.V. Webster, Traffic Signal Settings. London, England: Her Majesty's Stationery Office (1958)

8. H.C. Lorick, C.E. Wallace, R.E. Jamagin, Analysis of Fuel Consumption and Platoon Dispersion Models. University of Florida Transportation Research Center, Report No. UF-TRC-U32-TR-02 (1980)

9. V.A. Korchagin, Yu.N. Rizaeva, Otsenka effektivnosti inzhenernykh reshenii, Uchebnoe posobie. pod red. V.A. Korchagina [Assessment of the efficiency of engineering solutions: a tutorial. Ed. V.A. Korchagin]. Lipetsk: LSTU, 160 p. (2008)

10. A.N. Kotukhov, E.A. Novopisnyi, Ekonomika,dorozhnogo,dvizheniya 6 Ucheb. posobie [Traffic Economy: the textbook]. Belgorod: the BSTU named after V.G. Shuhov Publishing, 235 p. (2009)

11. Raschetnaya instruktsiya (metodika) po inventarizatsii vybrosov zagryaznyayushchikh veshchestv ot avtotransportnykh sredstv na territorii krupneishikh gorodov [Calculation instruction (technique, methodology) on the inventory of emissions of pollutants from motor vehicles on the territory of the largest cities]. Avtopolyus-plyus Publ., 2008,78 p.

12. V.A. Korchagin, A.N. Novikov, S.A. Lyapin, J.N. Rizaeva, I.A. Novikov, Complex self-developing transport systems. International Journal of Pharmacy and Technology, 8(3), pp. 15253-15261 (2016) 